\section{Unusual localization and translocation of TRPV4 protein in cultured ventricular myocytes of the neonatal rat}

\author{
Y. Zhao, H. Huang, Y. Jiang, H. Wei, \\ P. Liu, W. Wang, W. Niu \\ Department of Physiology and \\ Pathophysiology, Capital Medical \\ University, Beijing, China
}

\section{Abstract}

TRPV4 protein forms a $\mathrm{Ca}^{2+}$-permeable channel that is sensitive to osmotic and mechanical stimuli and responds to warm temperatures, and expresses widely in various kinds of tissues. As for cardiac myocytes, TRPV4 has been detected only at the mRNA level and there were few reports about subcellular localization of the protein. The purpose of the present study was to investigate the expression profile of TRPV4 protein in cultured neonatal rat ventricular myocytes. Using Western blots, immunofluorescence, confocal microscopy and immuno-electron microscopy, we have shown that TRPV4 protein was predominantly located in the nucleus of cultured neonatal myocytes. Furthermore, cardiac myocytes responded to hypotonic stimulation by translocating TRPV4 protein out of the nucleus. The significance and mechanism concerning the unusual distribution and translocation of TRPV4 protein in cardiac myocytes remain to be clarified.

\section{Introduction}

The transient receptor potential (TRP) channels have attracted increasing interest since the first member was found in a Drosophila mutant. ${ }^{1}$ Most of the TRP members are nonselective cation channels. The striking features of the TRP superfamily are the functional diversity and almost ubiquitous expression. While most TRP proteins are assembled into the sarcolemma to function, some TRP members may play a role in additional locations besides the cell membrane; for example, TRPP2 ${ }^{2,3}$ and TRPV4 $4^{4}$ may also be located in cell organelles (the endoplasmic reticulum and Golgi apparatus) as $\mathrm{Ca}^{2+}$ releasing channels. In addition, TRPML1 to ML3 are thought to be involved in proton-leak channels of intracellular endosomes and lysosomes. ${ }^{5}$

It has been reported that TRPV1, V2 and V4, ${ }^{6-8}$ TRPC1, C3 to C7, ${ }^{9-11}$ TRPM4 and M5 ${ }^{12,13}$ and
TRPP2 ${ }^{8,14}$ are expressed in cardiac myocytes. Accumulating evidence has also suggested that many TRP members are involved in intracellular $\mathrm{Ca}^{2+}$ regulation, cardiac hypertrophy and arrhythmias. So far, there are only very limited data that TRPV4 mRNA is expressed in adult cardiac muscles. ${ }^{8}$ Furthermore, there are no data about TRPV4 protein expression profile in cardiac myocytes. In the present study we reported our discovery that TRPV4 protein was unusually and predominantly localized in the nucleus of the cultured neonatal rat ventricular myocytes. Furthermore, TRPV4 was translocated out of the nucleus upon hypotonic stimulation.

\section{Materials and Methods}

All animal experimental procedures were approved by the Institutional Animal Care and Use Committee of the Capital Medical University, Beijing, China, and were performed in accordance with the Regulations for the Administration of Affairs Concerning Experimental Animals (State Science and Technology Commission, China, 1988).

\section{Cell culture}

Primary cultures of ventricular myocytes were prepared from 1-day-old Sprague-Dawley rats according to the method of Simpson. ${ }^{15}$ In brief, the ventricular tissue was digested by 84 U/mL collagenase type II (Worthington Biochemical, Lakewood Township, NJ, USA) and $50 \mathrm{mg} / \mathrm{mL}$ trypsin (Gibco, Carlsbad, CA, USA) at $37^{\circ} \mathrm{C}$ and then the cell suspension was centrifuged $(1000 \times \mathrm{g}, 10 \mathrm{~min})$. This digestion course was repeated 10-12 times. The harvested isolated ventricular myocytes were plated on $60 \mathrm{~mm}$ dishes at a field density of $6 \times 10^{5}$ $7 \times 10^{5}$ cells $/ \mathrm{cm}^{2}$ and cultured in Dulbecco's Modified Eagle Medium (DMEM, Gibco) supplemented with $10 \%$ fetal bovine serum (FBS, Hyclone, Adelaide, Australia) and $10 \mathrm{mM} \mathrm{5'-}$ BrDU (Roche, Grenzach-Wyhlen, Germany) with $5 \% \mathrm{CO}_{2}$ at $37^{\circ} \mathrm{C}$. The cells cultured for 3-6 days were used for this study.

\section{Immunofluorescence}

The ventricular myocytes cultured on coverslips were rinsed three times with cold phosphate buffer saline (PBS) and fixed in 4\% paraformaldehyde solution for $15 \mathrm{~min}$. The cells were then permeabilized with $0.1 \%$ Triton X-100 in PBS, and treated with $3 \% \mathrm{H}_{2} \mathrm{O}_{2}$ in absolute methanol. Normal goat serum (10\% in PBS) was used to block endogenous biotin. The cells were incubated with the anti-TRPV4 antibody (1:100 dilution, Alomone Labs Ltd., Jerusalem, Israel) at $4^{\circ} \mathrm{C}$ overnight, and then
Correspondence: Weizhen Niu and Wei Wang, Department of Physiology and Pathophysiology, Capital Medical University, Beijing 100069, P.R. China.

Tel. +86.10.83950094 - Fax: +86.10 .83911454 .

E-mail: niuwz@126.com; wangwei@ccmu.edu.cn

Key words: TRPV4, nucleus, hypotonicity, translocation, ventricular myocytes, neonatal rat.

Acknowledgments: this work was supported by the National Natural Science Foundation of China (30800377; 30770790; 31171105).

The authors kindly thank Dr. Dali Luo (Department of Pharmacology, Capital Medical University) for supplying the ultra-small gold secondary reagents of goat-anti-rabbit IgG.

Received for publication: 13 February 2012. Accepted for publication: 30 May 2012.

This work is licensed under a Creative Commons Attribution NonCommercial 3.0 License (CC BYNC 3.0).

(C) Copyright Y. Zhao, et al., 2012

Licensee PAGEPress, Italy

European Journal of Histochemistry 2012; 56:e32 doi:10.4081/ejh.2012.e32

incubated with goat anti-rabbit IgG secondary antibody conjugated with tetramethyl rhodamine isothiocyanate (TRITC) (1:100 dilution, ZSGB-BI0, Beijing, China) for $1 \mathrm{~h}$. The coverslips were then mounted on slides with $90 \%$ glycerol in PBS. The same labeling protocol was also used for freshly isolated neonatal and adult ventricular myocytes. Fluorescence signals were observed under a confocal fluorescence microscope with a $40 \times$ or $63 \times$ objective lens (LAS-AF-TCS SP5, Leica, Solms, Germany).

\section{Immunohistochemistry}

Immunoreactivity in the neonatal and adult rat ventricles was tested using avidin-biotinperoxidase reactions. Tissue paraffin sections of $3 \mu \mathrm{m}$ were routinely prepared. After blocking the endogenous biotin with normal goat serum, sections were incubated at $4^{\circ} \mathrm{C}$ overnight with rabbit anti-rat TRPV4 primary antibody (1:100 dilution, Alomone Labs Ltd.). Secondary biotinylated goat anti-rabbit IgG was subsequently applied, the immunoreactivity was visualized with streptavidin-biotin-peroxidase using 3, 3'-diaminobenzi-dine (SigmaAldrich, St. Louis, M0, USA) as a substrate, and sections of the adult ventricle were counterstained with hematoxylin to show nuclei. Images were visualized using an optical microscope (Vanox-T, Olympus, Tokyo, Japan) with a $40 \times$ objective lens, and were acquired using an Olympus DP70 camera as well as DP Controller software version 1.2. 


\section{Immuno-electron microscopy}

Cultured ventricular myocytes on coverslips were rinsed with PBS, fixed for $2 \mathrm{~h}$ in the fixative containing $0.3 \%$ glutaraldehyde and $4 \%$ paraformaldehyde in $0.1 \mathrm{M}$ phosphate buffer (PB) and postfixed for additional $2 \mathrm{~h}$ in $4 \%$ paraformaldehyde in PB. Before immunolabeling of TRPV4 proteins, the myocytes were penetrated by $0.3 \%$ Triton X-100 for $20 \mathrm{~min}$ and blocked by $6 \%$ fresh goat serum in $0.01 \mathrm{M}$ PBS. The myocytes were then incubated with the primary (1:1000 dilution, Alomone Labs Ltd.) and secondary antibodies (Ultra-small gold reagents of goat-anti-rabbit IgG, 1:50 dilution, Aurion, Wageningen, The Netherlands). The cells were fixed with glutaraldehyde (2\%) followed by a 2-h sliver enhancement process (RGent SE-EM, Aurion) and then a 2-h fixation with 1\% osmic acid. Subsequently, the cells were dehydrated step by step. After permeation (for $4 \mathrm{~h}$ ) and polymerization $\left(37^{\circ} \mathrm{C}\right.$ overnight and $60^{\circ} \mathrm{C}$ for $\left.48 \mathrm{~h}\right)$, ultra-thin sections $(60 \mathrm{~nm})$ were mounted on electron microscope grids. The grids were dyed by lead nitrate (for 20 min) and uranyl acetate (for $30 \mathrm{~min}$ ), and the immunolabeling were examined with a JEM1230 transmission electron microscope (JEOL, Tokyo, Japan) at $80 \mathrm{kV}$.

\section{RT-PCR and real-time PCR}

Total RNA was extracted with an RNeasy kit (Invitrogen, Carlsbad, CA, USA) from cultured neonatal ventricular myocytes and adult kidney (positive control) of the SD rat. The specific forward and reverse primers for rat TRPV4 were 5'-CCCCGTGGTCTTCATTCT-3' and 5'-CATCTGTGCCTGAGTTCTTGT-3' and those for $\beta$-actin were 5'-AAGATGACCCAGATCATGTT-3' and 5'-TTAATGTCACGCACGATTTC-3', respectively. PCR products (expected fragment sizes: TRPV4, 446 bp; $\beta$-actin, 287 bp) were analyzed on a $1.5 \%$ agarose gel by electrophoresis and visualized with ethidium bromide. The authenticity of amplified PCR products was verified using an ABI PRISM DNA sequencing system (Perkin Elmer, Boston, MA, USA).

Real-time PCR was performed according to a comparative quantitative analysis (Quick protocol of MxproTM QPCR software for Mx3000P system; Stratagene, La Jolla, CA, USA) in a total volume of $20 \mu \mathrm{L}$ using 96 -well microwell plates. A 45-cycle PCR program was carried out according to the following protocol: pre-denaturation for $10 \mathrm{~min}$ at $95^{\circ} \mathrm{C}$, denaturation for $30 \mathrm{sec}$ at $95^{\circ} \mathrm{C}$, annealing for $1 \mathrm{~min}$ at $57^{\circ} \mathrm{C}$ and elongation for $1 \mathrm{~min}$ at $72^{\circ} \mathrm{C}$. Forward and reverse primers, specific for rat TRPV4, were 5'-CAAGTGGCGTAAGTTCGG-3' and 5'-CCTGTGAGGAGCGTGATG-3', respectively. These primers yielded a 180-bp PCR product. Primers for $\beta$-actin were the same as those used in the RT-PCR experiments.

\section{Western blots}

Total protein was extracted from the cultured neonatal and the freshly isolated adult ventricular myocytes according to the reference. ${ }^{16}$ The cells were harvested in buffer $\mathrm{A}$ that containing (in mM) 50 Tris- $\mathrm{HCl}$ ( $\mathrm{pH} 7.5$ ), $50 \mathrm{NaF}, 2$ EDTA, 2 EGTA, 0.1 Na orthovanadate and 1 DTT with 2\% SDS and 15\% protease inhibitor cocktail (Roche). Homogenates were centrifuged at $33,000 \times \mathrm{g}$ for $30 \mathrm{~min}$ at $4{ }^{\circ} \mathrm{C}$. The supernatant (total proteins) was transferred and stored at $-80^{\circ} \mathrm{C}$.

Nuclear proteins were extracted by using a modified protocol (http://www.ualberta.ca/ $\sim$ olsonlab). In brief, the cultured neonatal ventricular myocytes were collected in buffer B containing (in mM) $10 \mathrm{HEPES}$ (pH 7.9 with $\mathrm{KOH}), 10 \mathrm{KCl}, 1.5 \mathrm{MgCl}_{2}, 0.1$ EDTA, 0.1 EGTA, 1 DTT and $15 \%$ protease inhibitor cocktail. The samples were placed on ice for $15 \mathrm{~min}$ after being disrupted by brief sonication and then exposed to $0.5 \%$ NP-40 followed by incubation on ice for $30 \mathrm{~min}$ and centrifugation at $6000 \times \mathrm{g}$ for $6 \mathrm{~min}$ at $4^{\circ} \mathrm{C}$. The sediment was then resuspended in buffer $\mathrm{C}$ containing (in mM) 20 HEPES (pH 7.9), $420 \mathrm{NaCl}, 1.5 \mathrm{MgCl}_{2}$, 0.1 EDTA, 0.1 EGTA and 1 DTT with $25 \%$ glycerol and 15\% protease inhibitor cocktail. The samples were centrifuged again at $33,000 \times \mathrm{g}$ for $30 \mathrm{~min}$ at $4^{\circ} \mathrm{C}$ after being placed on ice for $30 \mathrm{~min}$. The supernatant (nuclear proteins) was transferred and stored at $-80^{\circ} \mathrm{C}$.

Protein samples from cardiomyocytes (30 ug or 50 ug proteins) were separated by electrophoresis on an $8 \%$ polyacrylamide gel (for nucleus protein separation, a $12 \%$ gel was used) and transferred onto a cellulose acetate membrane. Nonspecific binding sites were blocked with $10 \%$ skim milk in Tris-buffered saline solution (TBS) ( $2 \mathrm{~h}$ at room temperature). The membrane was incubated with polyclonal anti-TRPV4 antibody (1:500 dilution, Alomone Labs Ltd.) in TBS solution with $0.05 \%$ Tween- 20 and $10 \%$ defatted milk powder (TBST-milk) at $4^{\circ} \mathrm{C}$ overnight with agitation. The antibody is directed specifically against a peptide of CDGHQQGYAPKWRAEDAPL, corresponding to amino acid residues 853-871 of rat TRPV4 (accession Q9ERZ8). After being washed, the membranes were then treated with IRDyeTM 700 conjugated affinity purified anti-rabbit secondary IgG for $1 \mathrm{~h}$ at room temperature, followed by three washes with TBST and two washes with TBS alone. Fluorescent bands were visualized using an LI-COR Odyssey infrared double-fluorescence imaging system (LI-COR Inc., Lincoln, NE, USA).

To compare the expression of TRPV4 before and after hypotonic stimulation both in the whole cell and the nucleus, we used $\beta$-actin as an internal loading control. It has been accepted widespread that $\beta$-actin is an indispensable constituent of nuclear proteins. ${ }^{17}$ The expression of $\beta$-actin was also demonstrated to be stable during exposure to hypotonicity. ${ }^{18}$

\section{Solution}

The isotonic solution $(300 \mathrm{~m} 0 \mathrm{sm} / \mathrm{L})$ contained (in mM) $100 \mathrm{NaCl}, 5 \mathrm{KCl}, 1 \mathrm{MgCl}_{2}, 10$ HEPES, 10 glucose, and 90 D-mannitol, and was adjusted to $\mathrm{pH} 7.4$ with $\mathrm{NaOH}$. The hypotonic medium $(210 \mathrm{~m} 0 \mathrm{sm} / \mathrm{L})$ was produced by omitting D-mannitol from the isotonic solution. The osmolarity of the solution was measured with an osmometer (Fiske 110, Fiske Associates, Norwood, MA, USA) at $0^{\circ} \mathrm{C}$.

\section{Data analysis}

Data were presented as the mean value \pm SEM. Student's paired and unpaired $t$-tests were performed by GraphPad Prism 4 software (GraphPad Software Inc., La Jolla, CA, USA). Values of $\mathrm{P}<0.05$ were considered statistically significant.

\section{Results}

\section{Localization of TRPV4 protein in cardiac myocytes}

Immunochemical analysis of TRPV4 protein was performed on ventricular myocytes. In freshly isolated neonatal myocytes, the TRPV4 immunological signal (TRPV4-TRITC, red) was mainly localized around the nucleus (Figure 1A). DAPI (blue) was used to stain the nucleus. In contrast, the immunological signal for TRPV4 was very strong in the nucleus of cultured neonatal myocytes (Figure $1 \mathrm{~B}$ 1), while the stain outside the nucleus was weak. Notably, TRPV4 immunoreactivity distribution in freshly isolated adult ventricular myocytes was similar to that in cultured neonatal cells (Figure 1C). In addition, we confirmed that TRPV4 protein was also mainly localized in the nucleus of neonatal and adult ventricular myocytes by immunohistochemistry (Figure 1 F,G). To exclude the possibility of a pseudo-positive reaction for the fluorescence signal in the nucleus, a blank control test without TRPV4 antibody was performed and a negative result was confirmed (Figure 1D). In addition, the positive signals for TRPV4 protein in the cultured ventricular myocytes disappeared in the antibody absorption test, demonstrating that the antibody was specific (Figure 1E). 


\section{Hypotonically induced transloca- tion of TRPV4 protein in cultured neonatal ventricular myocytes}

It has been reported that TRPV4 channel is activated by cellular swelling ${ }^{19}$ and translocation of TRPV4 protein in endothelial cells can occur in response to mechanical stimulations. ${ }^{4}$ To test the possibility of TRPV4 translocation in cultured neonatal ventricular myocytes when challenged by hypotonic stimulation $(210 \mathrm{m0sm} / \mathrm{L}, 45 \mathrm{~min})$, the distribution of TRPV4 protein before and after hypotonic exposure were compared.

Figure 2A shows a strong immunoreaction in the nuclear area for TRPV4 protein and a faint immunological signal outside the nucleus in the isotonic solution. However, after a 45-min hypotonic exposure, the fluorescence in the nuclear zone became much weaker while the extranuclear TRPV4 signal was enhanced (Figure 2B). Immuno-electron microscopy was used to further investigate the subcellular localization of TRPV4 protein in cultured ventricular myocytes before and after hypotonic treatment. TRPV4 immunoreaction clearly focused on the nuclear zone and less existed outside the nucleus (Figure 2C). After hypotonic stimulation (Figure 2D), the quantity of colloid gold granules in the nuclear area was greatly decreased, while immunogold labeling outside the nucleus was increased. These results reinforce the observation that hypotonic stimulation could trigger an outward translocation of TRPV4 protein from the nucleus.

RT-PCR analysis was performed to ascertain the expression of TRPV4 in ventricular myocytes. As shown in Figure $3 \mathrm{~A}$, mRNA for TRPV4 was detected in neonatal cultured ventricular myocytes and adult renal tissue (positive control) of the SD rat. The identity of the PCR product was further verified by sequencing (data not shown). Moreover, real-time PCR analysis was carried out to quantify the change of TRPV4 mRNA in neonatal cultured myocytes after hypotonic stimulation. Figure 3B showed that TRPV4 mRNA was not altered by hypotonic challenge $(P>0.05, n=12)$.

To further examine the expression and localization of TRPV4 at protein level, Western blot analyses were performed on the whole and the nucleus of cultured neonatal ventricular myocytes. The same two bands at $\sim 70$ and $\sim 90 \mathrm{kDa}$ were recognized with antiTRPV4 antibody in the freshly isolated adult (Figure 3C) and cultured neonatal ventricular myocytes (Figure 3D), and also in the nucleus fraction of the latter (Figure $3 \mathrm{E}$ ). Statistical analyses indicated that the quantity of TRPV4 protein in the whole cultured neonatal ventricular cell was not changed during the exposure to hypotonic solution (Figure $3 \mathrm{D}, \mathrm{F} ; \mathrm{P}>0.05 ; \mathrm{n}=5$ ), however, that in the nucleus fraction was significantly decreased (Figure $3 \mathrm{E}, \mathrm{F} ; \mathrm{P}<0.05 ; \mathrm{n}=15$ ), These results conformed our discovery in the immunocytochemical study that hypotonic stimulation resulted in translocation of TRPV4 protein outward from the nucleus in cultured neonatal ventricular myocytes.

\section{Discussion}

\section{Unusual localization of TRPV4}

protein in cultured ventricular myocytes of the neonatal rat

In this study, we showed that TRPV4 protein was expressed in ventricular myocytes of the neonatal rat (Figures 1, 2 and 3). TRPV4 pro-
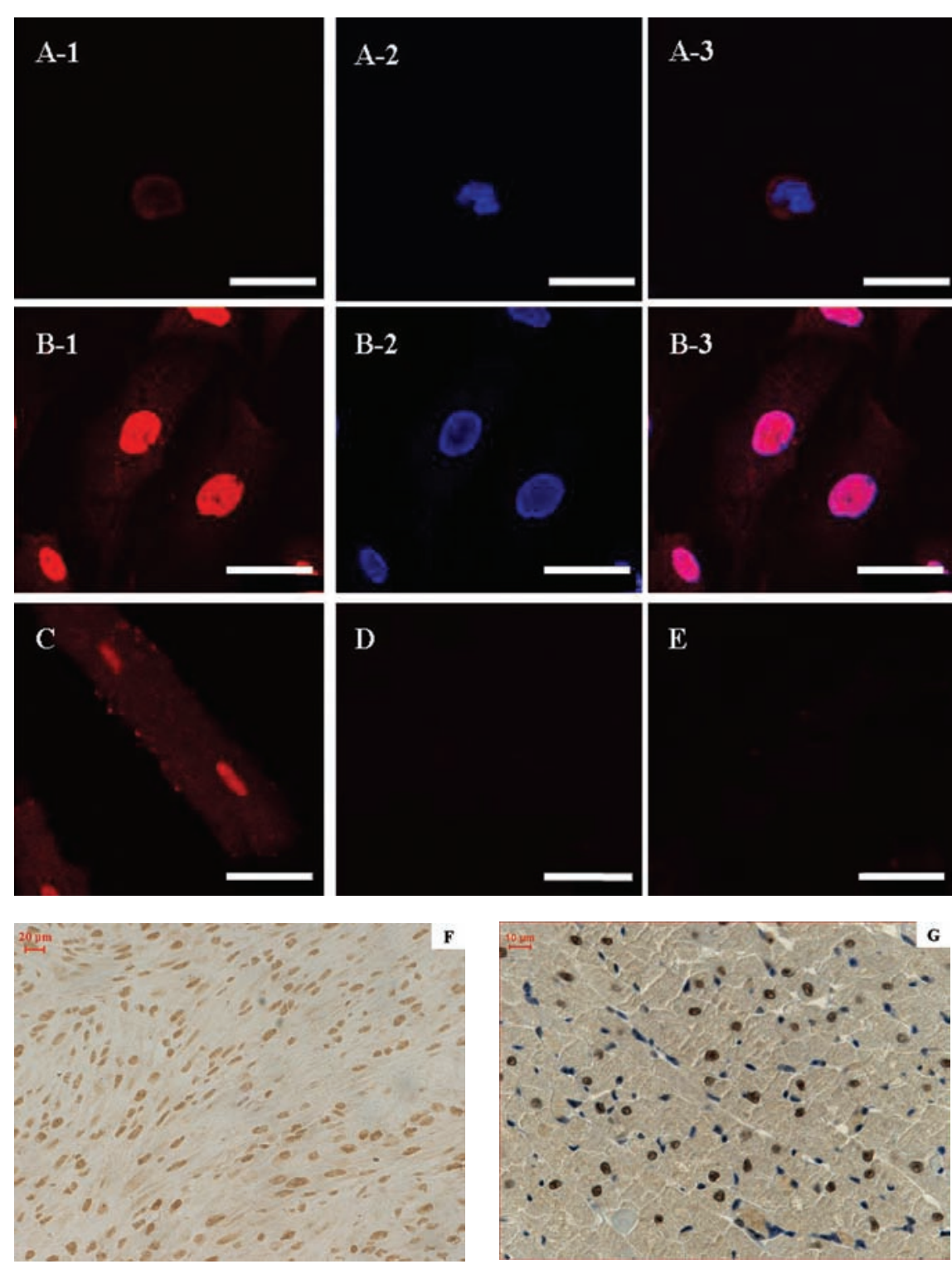

Figure 1. Localization of TRPV4 protein in cardiac myocytes. A, B) Confocal images of freshly isolated (A1-3, scale bar: $15 \mu \mathrm{m}$ ) and cultured neonatal ventricular myocytes (B13, scale bar: $25 \mu \mathrm{m}$ ) labeled with anti-TRPV4 antibody (A1 and B1) and DAPI (A2 and $B 2$ ), respectively, and the merged images (A3 and $B 3$ ). The freshly isolated neonatal ventricular myocyte was small and round. C) Confocal images of freshly isolated adult rat ventricular myocytes labeled with anti-TRPV4 antibody (scale bar: $25 \mu \mathrm{m})$. D) Confocal image of the cultured ventricular myocytes in blank control (without TRPV4 antibody). E) Confocal image of the cultured ventricular myocytes in absorption test, in which the anti-TRPV4 antibody was preincubated with the peptide antigen. F, G) Immunolabeling TRPV4 protein in sections of the neonatal and adult ventricles. 
tein has been thought to be inlaid in the cell membrane and to be assembled into ion channels. However, surprisingly, we found that the immunofluorescent signal of TRPV4 was extremely strong in the nucleus and seemed extraordinary. To confirm the antibody specificity and the authenticity of this phenomenon, four different experiments were performed. First, two types of negative control trials, blank and antibody absorption tests were carried out in immunofluorescence experiments. In both negative control experiments, positive signals could hardly be detected, demonstrating that the antibody was specific. Second, in Western blot analyses, the TRPV4 bands were not identified in the absorption tests (Figure 3C), which also verified the specificity of the TRPV4 antibody. Third, by means of immuno-electron microscopy, we confirmed that colloidal gold particles were localized in the cultured ventricular myocyte with a distinctly higher density in the nucleus (Figure 2C). Fourth, in the Western blot analyses on TRPV4 protein from the whole cell and nucleus, the same molecular mass of the bands confirmed the expression profile of TRPV4 protein (Figure $3 \mathrm{D}, \mathrm{E}$ ). Taken together, these results indicated that TRPV4 protein was located predominantly in the nucleus of cultured neonatal rat ventricular myocytes.

Human TRPV4 consists of 871 amino acids and has five variants including TRPV4-A (fulllength form), TRPV4-B (lacking exon 7), TRPV4-C (lacking exon 5), TRPV4-D (short deletion inside exon 2) and TRPV4-E (lacking $\Delta 237-284$ and $\Delta 384-444$ amino acids). ${ }^{18}$ The immunoreactive protein bands have apparent molecular masses of 96,100 and $110 \mathrm{kDa}$ for TRPV4-A and TRPV4-D, 91 and $96 \mathrm{kDa}$ for TRPV4-B, 92 and $97 \mathrm{kDa}$ for TRPV4-C, and 86 and $90 \mathrm{kDa}$ for TRPV4-E, respectively. The different bands for a particular variant were shown to be caused by glycosylation. ${ }^{20}$ In the mouse, wild type TRPV4 protein has a predicted molecular weight of $98 \mathrm{kDa} .{ }^{21}$ It was reported that anti-TRPV4 antibody detected two bands at $\sim 98$ and $\sim 107 \mathrm{kDa}$ in the kidney extract obtained from mice ${ }^{22}$ and in DRG neurons isolated from adult male rats. ${ }^{23}$ The isoform of $\sim 107 \mathrm{kDa}$ was considered as a glycosylated protein. Furthermore, Liedtke and Friedman ${ }^{24}$ detected a shorter isoform of 75 $\mathrm{kDa}$, which was thought to be a yet undescribed splice variant, in addition to the 107 $\mathrm{kDa}$ protein for TRPV4 in mouse kidney extract. In the present study, two similar bands of TRPV4 protein with molecular weights of $\sim 70$ and $\sim 90 \mathrm{kDa}$ were detected in adult and neonatal cardiomyocytes (Figure $3 \mathrm{C}, \mathrm{D}$ ).

Some reports have described that there are bright immunological signals in the nucleus for several types of channel proteins. TRPV4 immunoreactivity has been localized at the plasma membrane and in the nuclear and perinuclear areas of primary afferents isolated from mouse dorsal root ganglia ${ }^{25}$ and the organum vasculosum of the lamina terminalis. ${ }^{24}$ In many substantia nigra neurons, TRPV1 protein is stained as a punctuate-like pattern in the cytoplasm as well as the nucleus. ${ }^{26}$ Glazebrook et al. ${ }^{27}$ showed that TRPC6 immuno-signals occur in the nucleus of rat nodose ganglion neurons using the corresponding antibody of three different sources.
Furthermore, TASK1 immunofluorescence has been observed throughout plasmalemmal and intracellular locations, and TREK1 immunosignals are localized in all three cellular fractions of myometrial cells. ${ }^{28}$ We have also noticed a figure in a paper ${ }^{29}$ showing bright immunostaining for TREK1 both inside and outside the nucleus of the adult rat ventricular muscle and the transfected and cultured COS cell. Thus, it seems not uncommon that certain types of channel proteins could move into the
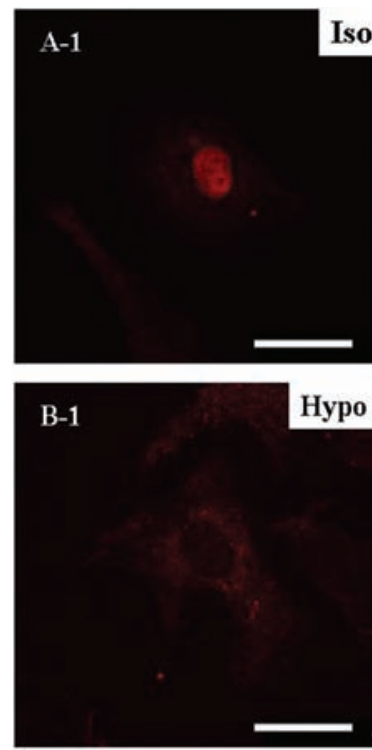

TRPV4
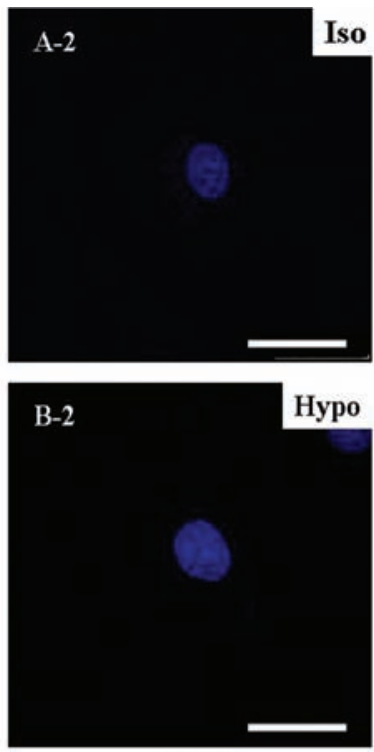

DAPI
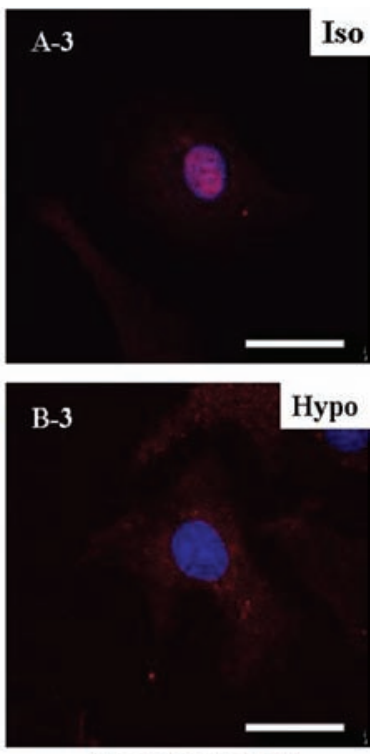

TRPV4+DAPI
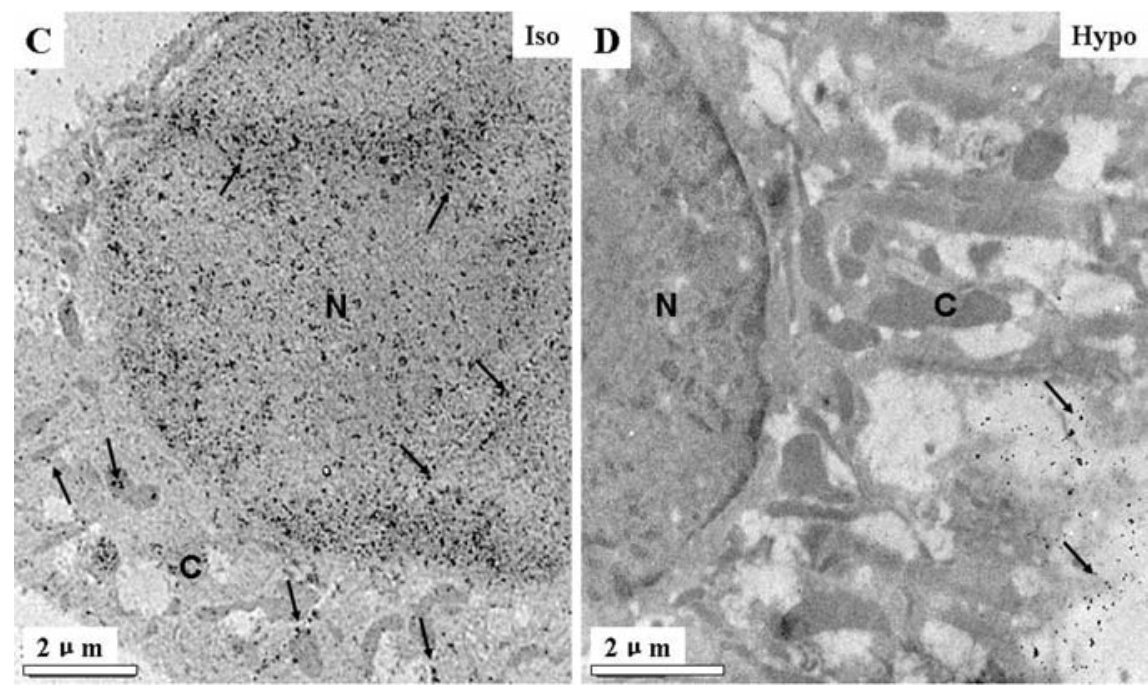

Figure 2. Effects of hypotonicity on the distribution of TRPV4 in ventricular myocytes. Iso and Hypo: isotonic and hypotonic bath solutions, respectively. A, B) Immuno-localization of TRPV4 protein in cultured ventricular myocytes before (A) and after (B) hypotonic stimulation (scale bar: $25 \mu \mathrm{m})$. The myocytes were doubly labeled for TRPV4 protein (A-1, B-1) and the nucleus (A-2, B-2) as did as in Figure 1. A-3 and B-3 were correspondingly overlaid images. C, D) Immunoreactivity of TRPV4 protein detected by immuno-electron microscopy in cultured ventricular myocytes before (C) and after (D) hypotonic stimulation. $\mathrm{N}$, nucleus; $\mathrm{C}$, cytoplasm; arrows indicate the colloidal gold granules. 
A

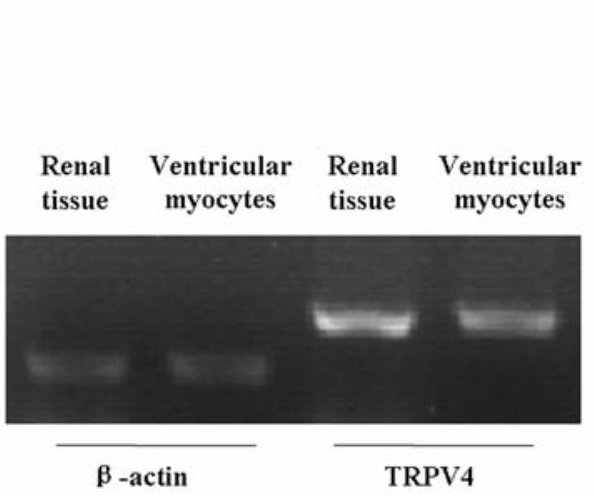

C

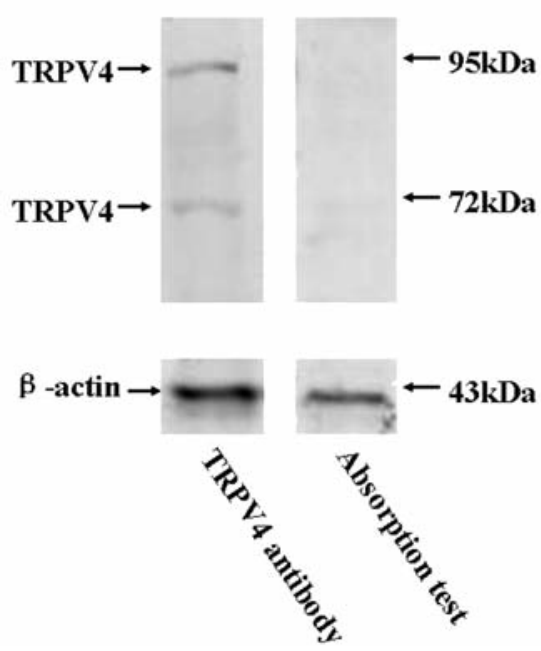

$\mathbf{E}$
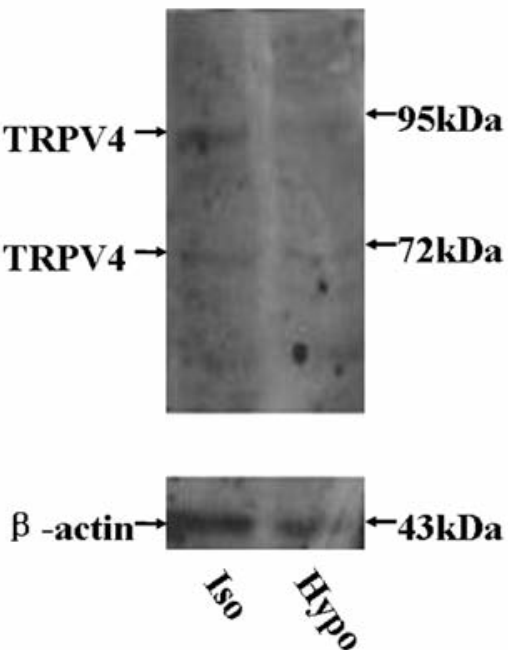

B

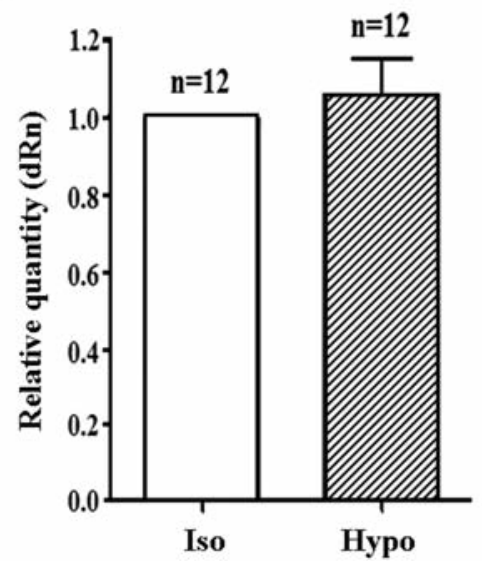

D

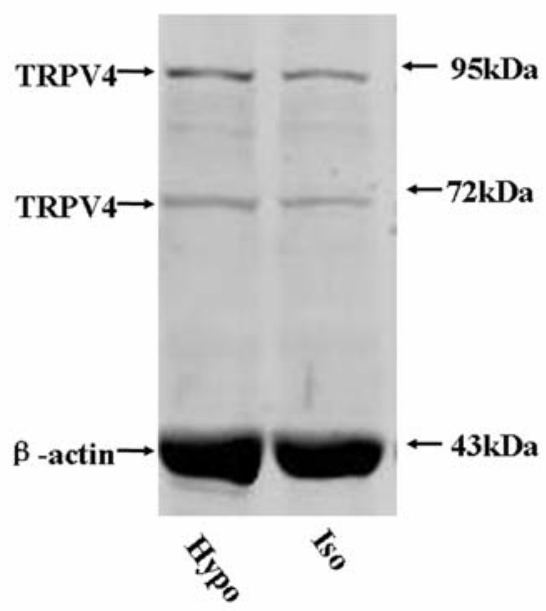

F

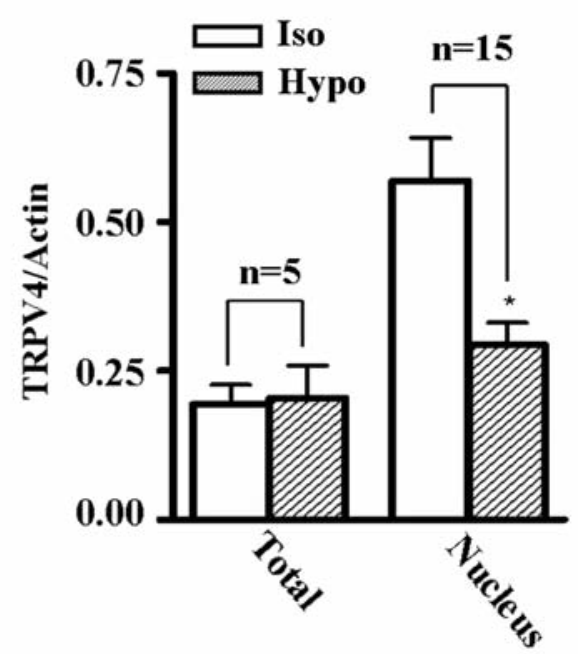

nucleus. There is evidence that multiple receptor tyrosine kinases, one type of membrane integrate proteins with a single transmembrane domain, could traffic to the nucleus in the full-length form. ${ }^{30,31}$ However, since TRPV4 protein contains six hydrophobic transmembrane-spanning domains, we guess that TRPV4 molecule would be more restrained by the lipid bilayer membrane when being transported into the nucleus. More investigations would be imperative for clarifying the mechanism of TRPV4 protein trafficking.

Polycystin-1, a TRPP2 related protein, can undergo proteolysis and release its carboxyterminal tail, which translocates to the nucleus and activates transcription factor AP1 ${ }^{32} \mathrm{~A}$ carboxy-terminal fragment of connexin 43 , a subunit of gap junction channel, has been localized in nuclei of the cardiomyocyte and HeLa cell and shown a non-channel function (to inhibit HeLa cell growth) ${ }^{33}$ It is possible that the immunofluorescence in our study might have been a reaction between the antiTRPV4 antibody and a TRPV4 peptide segment if it was cleaved proteolytically from the protein and transported into the nucleus. However, Western blot analyses on the molecular weight did not support an immunocomplex formed by a short TRPV4 peptide segment with its antibody. It also seems unlikely that a different protein with the same molecular weight could bind with the anti-TRPV4 antibody.

Figure 3. Hypotonically induced translocation of TRPV4 protein in cultured ventricular myocytes. A) The TRPV4 mRNA transcript was detected in adult renal tissues and cultured neonatal ventricular myocytes by RT-PCR amplification. B) Quantification of TRPV4 mRNA by real-time PCR for cultured ventricular myocytes in isotonic bath solution (Iso) and after hypotonic stimulation (Hypo). There were no significant differences at the mRNA levels between the two groups. C) Western blot analysis on the total TRPV4 protein of the freshly isolated adult ventricular myocytes and the corresponding absorption test. D) Western blot analysis on the total TRPV4 protein of cultured neonatal ventricular myocytes before and after exposure to hypotonic stimulation. E) Western blot analysis on TRPV4 protein in the nucleus fraction before and after hypotonic stimulation. F) Total and nuclear TRPV4 protein under isotonic and hypotonic conditions. The longitudinal coordinate stands for the relative ratio of TRPV4 fluorescent value contrast to $\beta$-actin fluorescent value $\left({ }^{*} \mathrm{P}<0.05\right)$. 


\section{Translocation of TRPV4 protein in cultured ventricular myocytes}

It is common for particular proteins, e.g., channels, to be translocated upon proper stimulations. Studies have demonstrated that insulin and insulin-like growth factor-I (IGF-I) enhance TRPV1-mediated membrane currents in heterologous expression systems and cultured dorsal root ganglion neurons. The enhancement of the membrane current results from both the increased sensitivity of TRPV1 and translocation of TRPV1 from cytosol to plasma membrane. ${ }^{34}$ Recently, Loot et al. ${ }^{4}$ reported that shear stress could induce translocation of TRPV4 from the Golgi apparatus to the cell membrane in cultured human endothelial cells. Cuajungco et al. ${ }^{35}$ found that co-expression of TRPV4 and PACSIN 3, a binding protein of TRPV4 and one member of the PACSIN family, increases the ratio of plasma membrane-associated versus cytosolic TRPV4. Moreover, microfilament-associated protein 7 has been implicated in increasing the membrane expression of TRPV4, ${ }^{36}$ and kinases of the WNK family have been reported to influence the function and localization of TRPV4. ${ }^{37}$ In the present study, TRPV4 protein was shown with unusual distribution profiles, dominant in the perinuclear region in freshly isolated neonatal ventricular myocytes and notable in the nucleus of cultured neonatal and freshly isolated adult ventricular myocytes. More importantly, TRPV4 protein moved out of the nucleus in response to hypotonic stress in cultured myocytes. These results strongly suggested that TRPV4 protein could shuttle into and out of the nucleus.

It has been suggested that TRPV4 can sense diverse physical stimuli and convert them to $\mathrm{Ca}^{2+}$ signals in various mammalian tissues. Mice lacking the TRPV4 gene have reduced regulation of serum osmolarity and an increased mechanical nociceptive threshold. ${ }^{24,38,39}$ Furthermore, TRPV4 functions as a transducer of hypo-osmotic stimuli in primary afferent nociceptors ${ }^{40}$ and plays an essential role in taxol-induced nociceptive behavioral responses to mechanical and hypotonic stimulations on the hind paw. ${ }^{41}$ All these functions are explained on the basis of its channel identity. However, in the present study, we provided new evidence that TRPV4 protein is located mainly in the nucleus of cultured neonatal ventricular myocytes and that TRPV4 protein was translocated out of the nucleus in responded to hypotonic stimulation. This nuclear localization of TRPV4 protein seems not in relation to channel functions. The significance of TRPV4 shuttling in cultured neonatal ventricular myocytes remains to be illuminated.

\section{References}

1. Montell C, Rubin GM. Molecular characterization of the drosophila trp locus: A putative integral membrane protein required for phototransduction. Neuron 1989;2: 1313-23.

2. Koulen P, Cai Y, Geng L, Maeda Y, Nishimura S, Witzgall R, et al. Polycystin-2 is an intracellular calcium release channel. Nat Cell Biol 2002;4:191-7.

3. Giamarchi A, Padilla F, Coste B, Raoux M, Crest $\mathrm{M}$, Honoré $\mathrm{E}$, et al. The versatile nature of the calcium-permeable cation channel TRPP2. EMBO Rep 2006;7:787-93.

4. Loot AE, Popp R, Fissithaler B, Vriens J, Nilius B, Fleming I. Role of cytochrome P450-dependent transient receptor potential V4 activation in flow-induced vasodilatation. Cardiovasc Res 2008;80:445-52.

5. Venkatachalam K, Hofmann T, Montell C. Lysosomal localization of TRPML3 depends on TRPML2 and the mucolipidosis-associated protein TRPML1. J Biol Chem 2006; 281:17517-27.

6. Iwata Y, Katanosaka Y, Arai Y, Komamura K, Miyatake K, Shigekawa M. A novel mechanism of myocyte degeneration involving the $\mathrm{Ca} 2+$-permeable growth factor-regulated channel. J Cell Biol 2003; 161:957-67.

7. Iwata Y, Katanosaka Y, Arai Y, Shigekawa M, Wakabayashi S. Dominant-negative inhibition of $\mathrm{Ca} 2+$ influx via TRPV2 ameliorates muscular dystrophy in animal models. Hum Mol Genet 2009;18:824-34.

8. Kunert-Keil C, Bisping F, Krüger J, Brinkmeier H. Tissue-specific expression of TRP channel genes in the mouse and its variation in three different mouse strains. BMC Genomics 2006;7:159-72.

9. Ohba T, Watanabe H, Takahashi Y, Suzuki T, Miyoshi I, Nakayama S, et al. Regulatory role of neuron-restrictive silencing factor in expression of TRPC1. Biochem Biophys Res Commun 2006;351: 764-70.

10. Ward ML, Williams IA, Chu Y, Cooper PJ, Ju YK, Allen DG. Stretchactivated channels in the heart: contributions to lengthdependence and to cardiomyopathy. Prog Biophys Mol Bio 2008;97:232-49.

11. Huang HX, Wang W, Liu P, Jiang Y, Zhao YQ, Wei H, et al. TRPC1 expression and distribution in rat hearts. Eur J Histochem 2009;53:e26.

12. Guinamard R, Demion M, Magaud C, Potreau D, Bois P. Functional expression of the TRPM4 cationic current in ventricular cardiomyocytes from spontaneously hypertensive rats. Hypertension 2006;48: 587-94.
13. Demion M, Bois P, Launay P, Guinamard R. TRPM4, a $\mathrm{Ca} 2+$-activated nonselective cation channel in mouse sino-atrial node cells. Cardiovasc Res 2007;73:531-8.

14. Inoue R, Jensen LJ, Shi J, Morita H, Nishida M, Honda A, et al. Transient receptor potential channels in cardiovascular function and disease. Circ Res 2006;99: 119-31.

15. Simpson P. Norepinephrine-stimulated hypertrophy of cultured rat myocardial cells is an alpha- 1 adrenergic response. $\mathrm{J}$ Clin Invest 1983;72:732-8.

16. Li JF, Niu CC, Han S, Zu PY, Li H, Xu QY, et al. Identification of protein kinase $\mathrm{C}$ isoforms involved in cerebral hypoxic preconditioning of mice. Brain Res 2005;1060:6272 .

17. Kumeta M, Yoshimura SH, Hejna J, Takeyasu K. Nucleocytoplasmic shuttling of cytoskeletal proteins: molecular mechanism and biological significance. Int J Cell Biol 2012;494902.

18. Zhang Z, Ferraris JD, Brooks HL, Brisc I, Burg MB. Expression of osmotic stressrelated genes in tissues of normal and hyposmotic rats. Am J Physiol Renal Physiol 2003;285:F688-93.

19. Arniges M, Vázquez E, FernándezFernández JM, Valverde MA. Swelling-activated $\mathrm{Ca} 2+$ entry via TRPV4 channel is defective in cystic fibrosis airway epithelia. J Biol Chem 2006;279:54062-8.

20. Arniges M, Fernández-Fernández JM, Albrecht N, Schaefer M, Valverde MA. Human TRPV4 channel splice variants revealed a key role of ankyrin domains in multimerization and trafficking. $\mathrm{J}$ Biol Chem 2006;281:1580-6.

21. Jin M, Wu Z, Chen L, Jaimes J, Collins D, Walters ET, et al. Determinants of TRPV4 activity following selective activation by small molecule agonist GSK1016790A. PLoS One 2011;6:16713-22.

22. Hartmannsgruber V, Heyken WT, Kacik M, Kaistha A, Grgic I, Harteneck C, et al. Arterial response to shear stress critically depends on endothelial TRPV4 expression. PLoS One 2007;2:e16713.

23. Alessandri-Haber N, Dina OA, Chen X, Levine JD. TRPC1 and TRPC6 channels cooperate with TRPV4 to mediate mechanical hyperalgesia and nociceptor sensitization. J Neurosci 2009;29:6217-28.

24. Liedtke W, Friedman JM. Abnormal osmotic regulation in trpv4-/- mice. Proc Natl Acad Sci USA 2003;100:13698-703.

25. Cenac N, Altier C, Motta J, d'Aldebert E, Galeano S, Zamponi GW, et al. Potentiation of TRPV4 signalling by histamine and serotonin: an important mechanism forvisceral hypersensitivity. Gut 2010;59: 481-8. 
26. Mezey E, Tóth ZE, Cortright DN, Arzubi MK, Krause JE, Elde R et al. Distribution of mRNA for vanilloid receptor subtype 1 (VR1), and VR1-like immunoreactivity, in the central nervous system of the rat and human. Proc Natl Acad Sci USA 2000;97: 3655-60.

27. Glazebrook PA, Schilling WP, Kunze DL. TRPC channels as signal transducers. Pflügers Arch 2005;451:125-30.

28. Bai X, Bugg GJ, Greenwood SL, Glazier JD, Sibley CP, Baker PN, et al. Expression of TASK and TREK, two-pore domain K+ channels, in human myometrium. Reproduction 2005;129:525-30.

29. Li XT, Dyachenko V, Zuzarte M, Putzke C, Preisig-Muller R, Isenberg G, et al. The stretch-activated potassium channel TREK-1 in rat cardiac ventricular muscle. Cardiovasc Res 2006;69:86-97.

30. Carpenter G, Liao HJ. Trafficking of receptor tyrosine kinases to the nucleus. Exp Cell Res 2009;315:1556-66.

31. Wang YN, Yamaguchi H, Hsu JM, Hung
MC. Nuclear trafficking of the epidermal growth factor receptor family membrane proteins. Oncogene 2010;29:3997-4006.

32. Chauvet V, Tian X, Husson H, Grimm DH, Wang T, Hiesberger T, et al. Mechanical stimuli induce cleavage and nuclear translocation of the polycystin-1 $\mathrm{C}$ terminus. J Clin Invest 2004;114:1433-43.

33. Dang X, Doble BW, Kardami E. The carboxy-tail of connexin-43 localizes to the nucleus and inhibits cell growth. Mol Cell Biochem 2003;242:35-8.

34. Van Buren JJ, Bhat S, Rotello R, Pauza ME, Premkumar LS. Sensitization and translocation of TRPV1 by insulin and IGF-I. Mol Pain 2005;1:17-28.

35. Cuaiungco MP, Grimm C, Oshima K, D'hoedt D, Nilius B, Mensenkamp AR, et al. PACSINs Bind to the TRPV4 Cation Channel-PACSIN 3 modulates the subcellular localization of trpv4. J Biol Chem 2006;281:18753-62.

36. Suzuki M, Hirao A, Mizuno A. Microtubuleassociated protein 7 increases the mem- brane expression of transient receptor potential vanilloid 4 (TRPV4). J Biol Chem 2003;278:51448-53.

37. Fu Y, Subramanya A, Rozansky D, Cohen DM. WNK kinases influence TRPV4 channel function and localization. Am J Physiol Renal Physiol 2006;290:F1305-14.

38. Suzuki M, Mizuno A, Kodaira K, Imai M. Impaired pressure sensation in mice lacking TRPV4. J Biol Chem 2003;278:22664-8.

39. Mizuno A, Matsumoto N, Imai M, Suzuki M. Impaired osmotic sensation in mice lacking TRPV4. Am J Physiol Cell Physiol 2003;285:C96-101.

40. Alessandri-Haber N, Yeh JJ, Boyd AE, Parada CA, Chen X, Reichling DB, et al. Hypotonicity induces TRPV4-mediated nociception in rat. Neuron 2003;39:497-511.

41. Alessandri-Haber N, Dina OA, Yeh JJ, Parada CA, Reichling DB, Levine JD. Transient receptor potential vanilloid 4 is essential in chemotherapy induced neuropathic pain in the rat. $\mathrm{J}$ Neurosci 2004; 24:4444-52. 